\title{
Building Rural Surgical Networks: An Evidence- Based Approach to Service Delivery and Evaluation
}

\author{
Création de réseaux ruraux pour la chirurgie : une \\ démarche fondée sur les données probantes pour \\ l'évaluation et la prestation des services
}

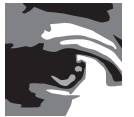 \\ JUDE KORNELSEN, PHD \\ Associate Professor, Department of Family Practice \\ University of British Columbia \\ Vancouver, BC \\ RANDY FRIESEN, MD \\ General Surgeon \\ Prince Albert, SK
}

\begin{abstract}
Formalized rural health service delivery networks are emerging as an over-arching response to the attrition of rural surgical and maternity services in Canada. In effective networks, there is strong collaborative leadership, form follows function, core network elements are identified and site-specific variations are accommodated to meet the surgical needs of the population in each geographic catchment. The network catchment must reflect the natural alliances that already exist among health professionals, policy makers, health administrators, academic institutions and communities. Although each key stakeholder plays a key role in determining success, value is added through the synergistic interplay of all participants.
\end{abstract}

\section{Résumé}

Les réseaux officiels de prestation des services de santé constituent une réponse à l'attrition des services ruraux de maternité et de chirurgie au Canada. Dans les réseaux efficaces, il y a un fort leadership de collaboration, la forme suit la fonction, les éléments centraux sont définis et on tient compte des variations locales pour répondre aux besoins en chirurgie de chaque bassin géographique. Le bassin d'un réseau doit correspondre aux alliances naturelles qui existent déjà entre les 
professionnels de la santé, les responsables de politiques, les administrateurs de la santé, les institutions universitaires et les communautés. Bien que chaque intervenant clé joue un rôle important pour assurer la réussite d’un réseau, la réciprocité synergétique de tous les participants y ajoute de la valeur.

\section{A Case for the Need for Networks in Rural Health Services Delivery} The recent publication of the Joint Position Paper on Rural Surgery and Operative Delivery (Iglesias et al. 2015) was remarkable, not only due to the cross-professional endorsement procured (College of Family Physicians of Canada, Society of Obstetrics and Gynecology Canada, Canadian Association of General Surgeons and the Society of Rural Physicians of Canada) but also due to the clear template it provided for the effective delivery of surgical services to rural communities. The position paper arises from the expressed need to curb the attrition of rural surgical and maternity services across Canada, a phenomenon reflective of international trends in rural healthcare. The suggested framework for an effective and sustainable solution rests on networks of care between rural, regional and tertiary settings.

Networks of health service delivery are not a new construct, based as they are on appropriate triage from low-resource levels of care (typically rural) to secondary and tertiary care (typically large urban centre), and the attendant socio-professional relationships involved in such healthcare transitions. Rural communities in Canada have depended on and thrived within these networks. Current attention to the efficacy of networks as a rural health services solution is based on formalizing and optimizing naturally occurring constructs for the purposes of development and support. Two caveats apply: form must follow function and, although core network elements may be identified, there will be natural and essential site-specific variation (one size does not fit all). Furthermore, the development of such networks must be based on geographic population catchments, and it is the responsibility of the network to meet the surgical needs of the entire population within its geography. This requires determining the appropriate location of care to meet the needs of the patient from rural to referral to tertiary.

For rural surgical and obstetrical services, this implies a regional organization of the scope of practice and resources required to implement surgical programs, decided through consensus agreement between the sites. A network may emerge between a referral centre and one or more rural sites. The BC Joint Standing Committee on Rural Issues report, The Sustaining of Small Rural Surgical Services in British Columbia (Grzybowski and Kornelsen 2013b), identified characteristics of rural surgical/perinatal surgical networks. Summarized, they include the assumption that rural surgical and obstetrical programs become outreach extensions of core referral hospital surgical programs, and the organization of services respects the sustainability of both the regional programs and the rural programs. The degree of integration in the program may vary depending on influencing factors, the most prominent being the degree of isolation of the smaller service. We would anticipate highly integrated networks being relatively proximal to regional referral centres, with a viable but different surgical relationship (network) model for more isolated settings. 
Although examples of "mandated cooperation" (institutionalization) of networks exist in highly structured administrative contexts, for independent and autonomous players in the care system (care providers, administrators and rural communities), voluntary collaboration would likely be more satisfying and enduring. The originating ethos behind the network will influence the ultimate framework, despite the potential of fluidity of form - fluidity that likely remains with the maturation of the network.

\section{Building Networks: The Physical Profile}

The geo-physical system "container" for the networks reflects the natural referral patterns between rural and regional referral sites across a geography formalized into population catchment areas surrounding each hospital facility (for example, the population within one-hour surface travel time of each facility). The sum total of the facilities-based catchments across a region forms the integrated or "meta catchment" for the network - the framework through which all evaluative and improvement activities can occur (Grzybowski and Kornelsen 2013a). This positions the location in which a procedure takes place as a network outcome, and supports and allows timely and regular feedback to the individual services within a quality improvement envelope. Again, the network catchment must not be an artificial construct, but instead, reflect the natural alliances that already exist - or could exist. From this starting point, more pragmatic planning can take place.

Of all the qualities of highly functional health services networks, collaboration and trust have been noted as paramount (Bonk 2000; Kilbride et al. 2011). Although good facilitation and leadership, as well as repeated interactions among network players, are necessary to develop these core qualities, they need to be underscored by a shared recognition of mutual benefit of network activities arising from all players. Furthermore, just as trust is the leading criteria for successful networks, lack of trust is the primary reason for network failure. Trust may be fostered through leadership that has the social authority to validate both the network and the need for the network (Robeson 2009).

When applied to surgical networks, on-the-ground leadership from a mutually respected party is essential. This may require a combination of clinical and administrative leadership with established credibility and acceptance by all involved. This key role must be filled by someone having the capacity to provide direct or indirect support for the tasks of its members, enabled by a supporting infrastructure to focus resources and allocate responsibilities. The core leadership attribute of "boundary spanning" refers to the individual's or groups' capacity to "reach across borders, margins or sections to build relationships, interconnections and interdependencies in order to manage complex problems" (Williams 2002).

Alongside building the network scaffolding, applied and pragmatic work needs to occur, including developing a clear and consensus-based statement of the networks' purpose, goals and objectives and the most effective communications infrastructure for both administrative and clinical communication (Bonk 2000; Robeson 2009; Woodland and Hutton 2012). A likely enabler will be new interpretations of telehealth, judiciously applied, to augment 
existing established communication, both within the network and more broadly between professions. This can allow the development of communities of practice (Wenger et al. 2002) within the network, which have been shown to act cohesively by reinforcing interprofessional collaboration and reducing the geographic and social isolation of members. Simultaneously, with the development of communities of practice is the need for an articulation of appropriate membership and attendant roles and function. The principle of inclusion for network membership must be maintained, but within the pragmatic confines of productivity (the capacity to manage). Research literature notes the imperative for clearly defined roles leading to increased participation and efficiency.

\section{Applying Network Concepts to Surgical Services in Rural Canada}

As it is inherently contingent on productive relationships between key stakeholders, network development in rural Canada may benefit from a formal articulation of players that warrant inclusion. Woollard (2006) worked to identify the "pentagram partners" in a social accountability framework. He non-hierarchically included health professionals, policy makers, health administrators, academic institutions and communities (Woollard 2006). Although each plays a key role in determining success, it is the synergistic interplay that increases the likelihood of success. For example, administrators must be intimately involved in decisions regarding the clinical scope of practice in each site to ensure that the appropriate resources are available. The procedures available in the local site must respond to the demographic needs of the population (community) and an evaluative framework must be in place to measure both process and summative outcomes of the model (academia) to enable course correction if necessary.

The reporting and examination of outcomes are now recognized as challenges for all of surgical practice. Networks can deliver outcome data at a population catchment level in a format amenable to the National Surgical Quality Improvement Program (NSQIP) analysis, making a strong evaluation framework a by-product of network development. Additional population health data can be measured, tracked and linked to both health outcomes and health system measures, including volume and scope of surgical procedures in each site, wait times and patient and provider-reported data such as satisfaction.

A by-product of the inclusion of the pentagram partners is the synergistic alignment necessary to increase communication between, for example, clinical teams that feel their Health Authority leadership may be out of touch with the reality of front-line care. Likewise, the deliberate inclusion of community representation ensures a service responsive to the needs of communities as opposed to the practitioner- or administrator-centred needs. Importantly, this engagement framework will support necessary discussions with regional surgical organizations at a provincial level to create jurisdictionally responsive scopes of practice to respond to the needs of the local population.

A realistic appraisal of challenges is essential in network development, starting with those that, if not resolved, preclude growth and sustainability. In the case of rural surgical 
networks in Canada, such a "deal-breaker" is the productive interprofessional relationships between family physicians and their specialist colleagues, whom they rely on for clinical mentorship and support. Although historically this has been challenging, particularly the relationship between family physicians and general surgeons (Kornelsen et al. 2013), the multi-party endorsement of the Joint Position Paper signals a new era, at least with organizational leadership. Creating the conditions for this ethos of collaboration to flourish among members on the ground, however, will be essential in realizing the vision. This may be done in part by ensuring greater transparency of Family Physicians with Enhanced Surgical Skills (FPESS) training and the adherence to a standardized curriculum with interprofessional assessment of skills (Caron et al. 2015), but it is also required that this transparently extend to the day-to-day clinical practice of the rural sites by involving FPESS in itinerant surgeries or providing support for FPESS procedures at their sites. Other mechanisms of inter-site relationship building will include network-based continuing education and professional development involving a cross-section of network membership from multiple sites, integrated multi-site patient review and collaborative review of outcomes data.

Building the environment in which networks can flourish requires the investment of capital to facilitate, for example, expanded operating room days for specialists in the rural sites, additional equipment that may be necessary, additional nursing lines for pre-operative, operative and post-operative care, but also a mechanism for engaging key stakeholders to position the network in a way that responds to local needs (i.e., sessional fees for meeting to plan). With these key supports in place, there is a strong potential for effective and sustainable surgical and maternity care networks across rural Canada.

\section{Rural Surgical Networks in Canada: The Way Forward}

We must approach the development of rural surgical networks in Canada with a sense of cautious optimism that acknowledges the variation in support among general surgeons and across geography. In a recent qualitative study with general surgeons from Western Canada on specialists' perceptions of FPESS (Kornelsen et al. 2016), participants thematically expressed concerns over training, competence and avenues for Continuing Medical Education and Continuous Quality Improvement. Almost all participants emphasized the need for a standardized educational curriculum and evaluation process for family physicians providing procedural care; currently, the only accredited postgraduate program in Canada that provides such training is at the University of Saskatchewan's Prince Albert site. Such a curriculum has been developed and proposed by the National Working Group on Enhanced Skills (Caron et al. 2015) to both standardize skills and to ensure a low-volume rural practice focus is maintained. Levels of support for enhanced surgical skills is even more fractured by geography with general surgeons in Western Canada and the far North more amenable than their colleagues in Central and Eastern Canada, due, in part, to geography and historical precedent.

Networks of rural surgery and maternity care are emerging as an over-arching solution to cement the sustainability and viability of small surgical services in Canada. They are, however, 
not a panacea for the structural challenges that have beset healthcare across rural Canada. These include larger debates on the value and efficacy of generalism versus specialization and the attendant interprofessional discordance these debates evoke. There are clinical concerns, such as the safety of procedural care in low-volume services and professional concerns regarding the need for a standardized curriculum and attendant evaluation and monitoring framework that must be addressed by best available evidence. With the development of networks, there is a place to address these difficulties as they will demand and provide an approach and venue for respectful dialogue. Ultimately, we are closer than we have been for the past several decades to fashioning a solution that can address the healthcare needs of rural residents. Grounding our activity in meeting this objective will ensure we stay the course.

Correspondence may be directed to: Jude Kornelsen, PhD, Associate Professor, Department of Family Practice, 5950 University Boulevard, Vancouver, BC, V6T 1Z3; tel.: 250-653-4325; e-mail: jude.kornelsen@familymed.ubc.ca.

\section{References}

Bonk, G. 2000. Principles of Rural Health Network Development and Management. Washington, DC: Alpha Center. Caron, N., S. Iglesias, R. Friesen, V. Berjat, N. Humber, R. Falk et al. 2015. "A Proposal for the Curriculum and Evaluation for Training Rural Family Physicians in Enhanced Surgical Skills." Canadian Journal of Surgery 58(6): 419-22. doi:10.1503/cjs.002215.

Grzybowski, S. and J. Kornelsen. 2013a. "Rural Health Services: Finding the Light at the End of the Tunnel." Healthcare Policy 8(3): 10-16. doi:10.12927/hcpol.2013.23207.

Grzybowski S. and J. Kornelsen. 2013b. The Sustaining of Small Rural Surgical Services in British Columbia. Centre for Rural Health Research, BC. Retrieved July 12, 2016. <http://ess.rccbc.ca/wp-content/uploads/ sites/5/2014/12/JSC-Report-Feb-1.pdf>.

Iglesias, S., J. Kornelsen, R. Woollard, N. Caron, R. Friesen, P. Miles et al. 2015. “Joint Position Paper on Rural Surgery and Operative Delivery." Canadian Journal of Rural Medicine 20(4): 129-38.

Kilbride, C., L. Perry, M. Flatley, E. Turner and J. Meyer. 2011. "Developing Theory and Practice: Creation of a Community of Practice through Action Research Produced Excellence in Stroke Care." Journal of Interprofessional Care 25(2): 91-97. doi:10.3109/13561820.2010.483024.

Kornelsen, J., S. Iglesias, N. Caron and S. Moole. 2016. Specialists' Perceptions of Family Physicians with Enhanced Surgical Skills: Findings from an Evaluative Qualitative Study. Poster presented at the Summit on Rural Surgery and Operative Delivery, Banff, Canada. Poster retrieved from: <www.srpc.ca/ess2016/summit/GPESS.POSTER.KORNELSEN.pdf>.

Kornelsen, J., S. Iglesias, N. Humber, N. Caron and S. Grzybowski. 2013. "The Experience of GP Surgeons in Western Canada: The Influence of Interprofessional Relationships in Training and Practice." Journal of Research in Interprofessional Practice and Education 3(1): 43-61.

Robeson, P. 2009. Networking in Public Health Exploring the Value of Networks to the National Collaborating Centres for Public Health. Hamilton, ON: National Collaborating Centre for Methods and Tools, pp. 3-84.

Wenger, E., R.A. McDermott and W. Snyder. 2002. Cultivating Communities of Practice: A Guide to Managing Knowledge. Boston, MA: Harvard Business Press.

Williams, P. 2002. “The Competent Boundary Spanner." Public Administration 80(1): 103-24. doi:10.1111/1467-9299.00296.

Woodland, R. and M. Hutton. 2012. "Evaluating Organizational Collaborations: Suggested Entry Points and Strategies." American Journal of Evaluation 33(3): 366-83. doi:10.1177/1098214012440028.

Woollard, R.F. 2006. "Caring for a Common Future: Medical Schools' Social Accountability." Medical Education 40(4): 301-13. doi:0.1111/j.1365-2929.2006.02416.x. 